\title{
CARCINOMA PAPILAR DE NASOFARINGE EN UNA PACIENTE DE 13 AÑ̃OS
}

Martín Pinzón Navarro, MD*, Ricardo Guerra Fuentes, MD**, Carlos García Hurtado, MD***

\section{Resumen}

El carcinoma papilar de nasofaringe es una patología poco frecuente en la población mundial encontrando reportes en la literatura oriental y europea. Se presenta este caso clínico y una revisión de la literatura reciente como material didáctico para el aprendizaje.

Palabras clave: carcinoma de nasofaringe, carcinoma papilar.

\section{NASOPHARYNGEAL PAPILLARY CARCINOMA IN A 13-YEAR OLD FEMALE PATIENT}

\begin{abstract}
Nasopharyngeal papillary carcinoma is a rare neoplasm worldwide. It is described in Eastern and European literature. We present this clinical case and a literature review for didactic purposes.
\end{abstract}

Key words: nasopharyngeal carcinoma, papillary carcinoma.

\section{Introducción}

El carcinoma de nasofaringe es un tumor raro en nuestra comunidad, pero común en poblaciones del sudeste de Asia. En Colombia es prevalente en la costa pacífica existiendo una asociación con el virus de Epstein Barr; sin embargo, no se ha encontrado una relación entre este virus y la aparición del carcinoma papilar de nasofaringe, recordando que es rara la presentación en dicho nivel. ${ }^{1-4}$

\section{Caso clínico}

Paciente de trece años, raza negra, natural y procedente de Bogotá, que acude a la consulta del servicio de Otorrinolaringología del Hospital de San José, Bogotá D.C. Colombia, con un cuadro clínico de cinco años de evolución caracterizado por obstrucción nasal bilateral, respiración oral, roncopatía, epistaxis intemitente relacionada con maniobras de valsalva, sin rinorrea ni escurniniento poste-
Fecha recibido: marzo 8 de 2010 Fecha aceptado: junio 17 de 2010

* Otorrinolaringólogo, cirujano plástico facial, cirujano maxilofacial. Docente programa de Otorrinolaringología de la Fundación Universitaria de Ciencias de la Salud. Hospital de San José. Bogotá D.C. Colombia.
** Residente IV año del programa de Otorrinolaringología. Fundación Universitaria de Ciencias de la Salud. Hospital de San José. Bogotá D.C. Colombia.

*** Residente II año del programa de Otorrinolaringología. Fundación Universitaria de Ciencias de la Salud. Hospital de San José. Bogotá D.C. Colombia. 
rior. Al examen físico la paciente presenta respiración oral, mordida abierta clase III e hipoplasia del tercio medio facial. Como antecedente, el núcleo familiar de la paciente es de la costa Pacífica. Los demás datos son negativos.

En la tomografía de senos paranasales de ingreso se evidencia una masa que ocupa la nasofaringe y se extiende hacia las coanas obstruyéndolas sin realzarse con el medio de contraste (Figura 1). Se realizó nasosinuscopia encontrando septum funcional, cornetes inferiores eutróficos, masa rosada que ocupa ambas coanas en su totalidad, de borde liso, sin ulceraciones, no pulsátil. Se solicitó resonancia nuclear magnética de senos paranasales, simple y contrastada observando masa de contormos bien definidos sin extensión ósea, con dimensiones de 32 × 20 $\mathrm{mm}$ que resalta con medio de contraste (Figura 2).

Se realizó un primer tiempo quirúrgico diagnóstico con reporte de patología de lesión tumoral maligna de arquitectura papilar revestida por epitelio cúbico y cilíndrico simple, con hendiduras y pseudoinclusiones nucleares, escasas mitosis, con estroma colágeno y tallos fibrovasculares asociados con infiltrado inflamatorio mixto de tipo mono y polimorfonuclear. Los estudios de inmunohistoquímica fueron positivos para CK-7, TTF1 y tiroglobulina; la CK-20 y S-100 fueron negativos, hallazgos compatibles con carcinoma papilar. Se realizaron estudios para descartar origen primario tiroideo:
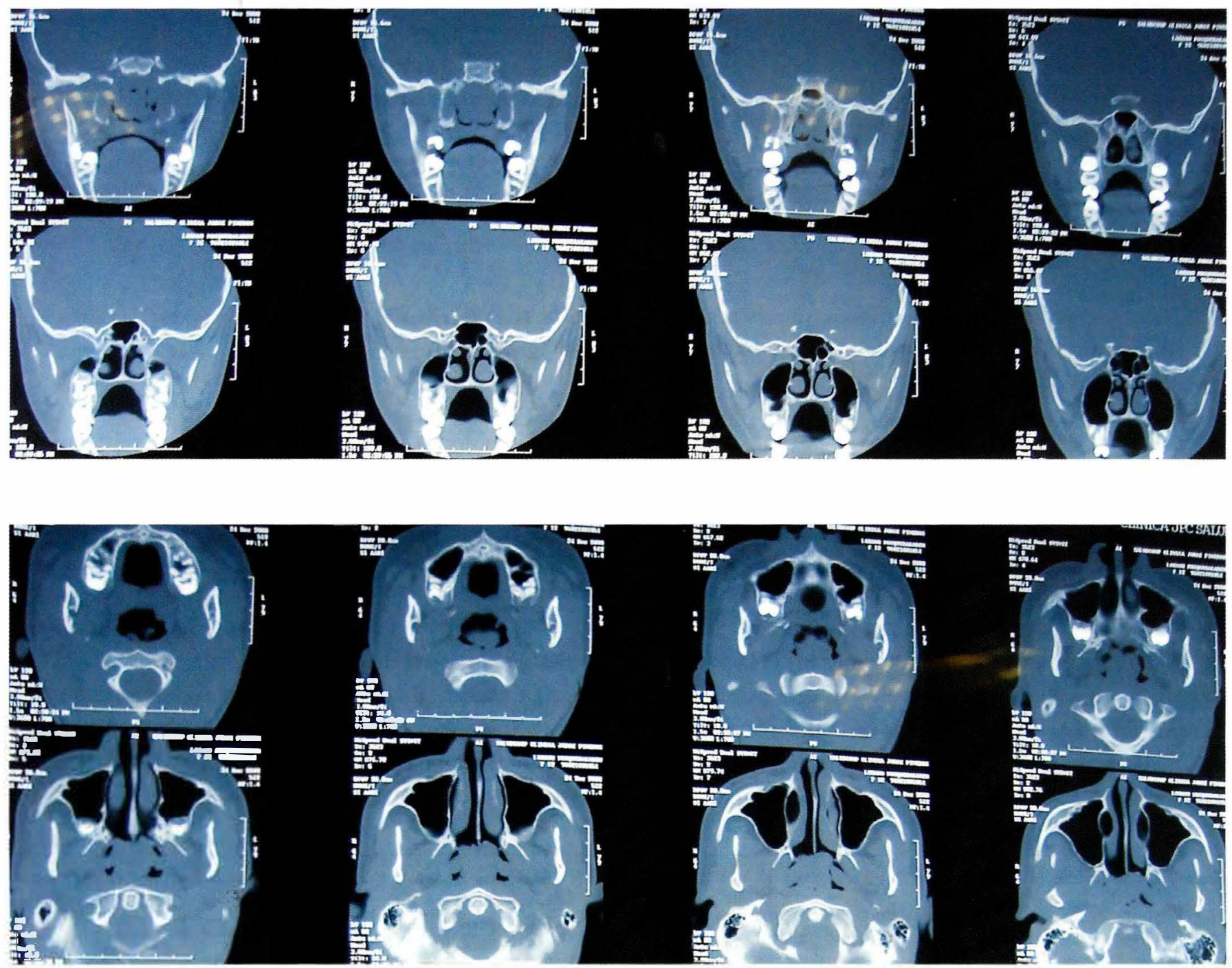

Figura I. Tomografía de senos paranasales. 


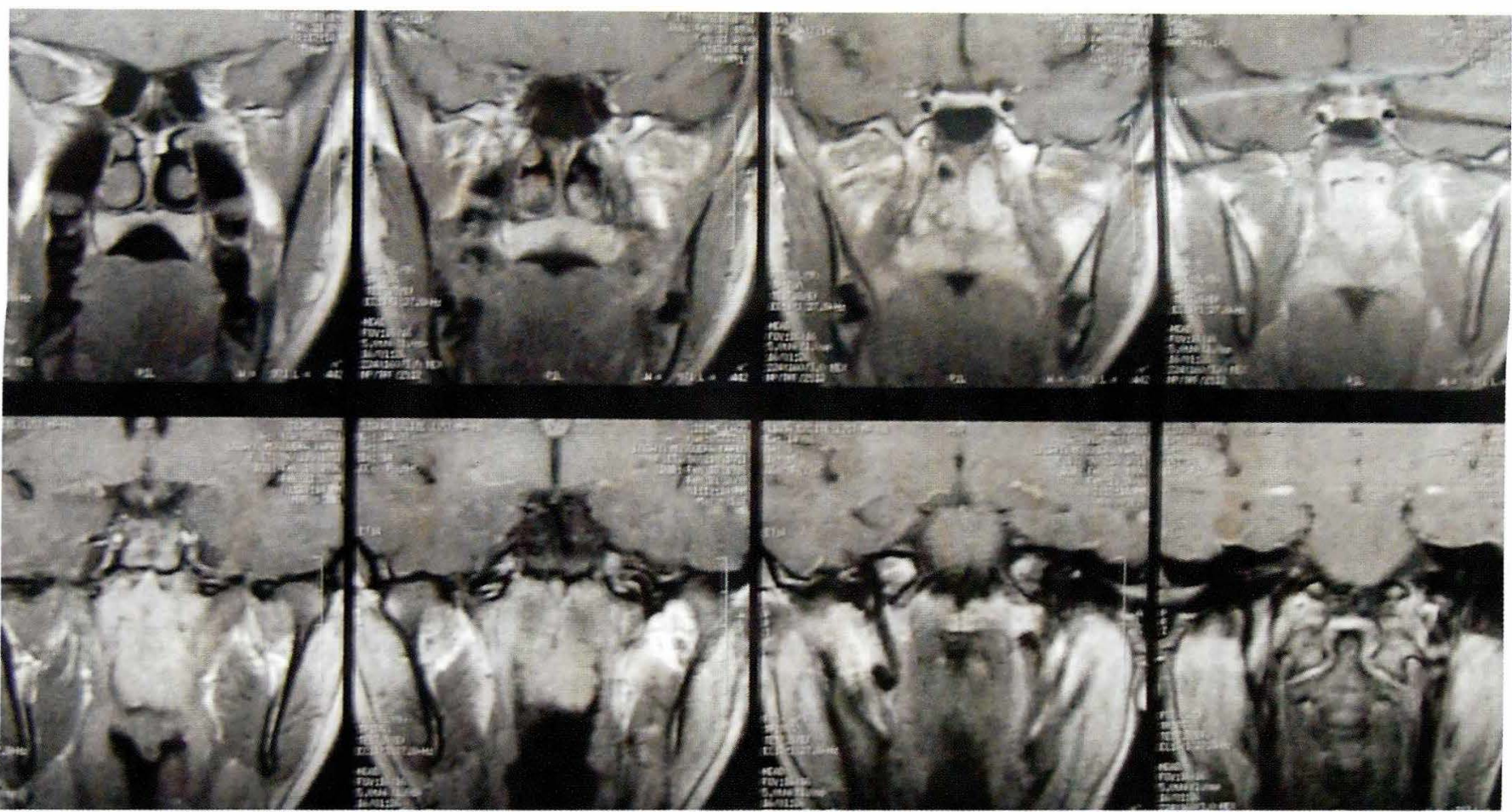

Figura 2. Resonancia nuclear magnética.

ecografía de alta resolución que reportó glándula normal, ganglios de morfología usual con aumento de tamaño de los correspondientes a zonas IIA y IIB bilateral, biopsia aspiración con aguja fina de tiroides con proliferación linfoide atípica, radiografía de tórax y pruebas de función tiroidea dentro de límites normales. Con lo anterior se clasificó la lesión en estadio I (TI,N0,M0) según la AJCC. ${ }^{3}$ (Tabla 1).

Se llevó a segundo tiempo quirúrgico vía endoscópica para realizar la resección de la lesión realizando extracción en bloque y enviando biopsia por congelación, logrando bordes laterales, superiores e inferiores negativos para tumor a $1.5 \mathrm{~cm}$ de la lesión y margen profundo negativo. En el posoperatorio la paciente presenta mejoría de la obstrucción nasal y la roncopatía. Se realizaron además estudios de extensión (resonancia nuclear magnética de abdomen, tomografía computarizada de tórax y gammagrafía ósea corporal total), los cuales fueron negativos para malignidad. A la fecha, sin evidencia de recidiva tumoral por nasosinuscopia de control.

\section{Discusión}

El carcinoma de nasofaringe se presenta en zonas endémicas del sudeste de Asia en Taiwán y Hong Kong. En nuestro país se presenta con mayor frecuencia en la zona pacífica de los departamentos del Valle y Cauca, probablemente debido a la migración de población asiática hace 75 años cuando se establecieron en Jagual, Corinto, departamento del Cauca. ${ }^{5}$ Sin embargo, el carcinoma papilar de nasofaringe es raro aún en la población donde es endémico el de nasofaringe. La mayoría de los carcinomas de estos últimos son de tipo queratinizado y no queratinizado y es rara la diferenciación glandular; cuando se presenta pueden ser en su mayoría de glándulas salivares submucosas. Debido a la baja presentación de este tipo de tumores a nivel de la nasofaringe se recomienda siempre realizar todos los estudios de extensión para descartar metástasis u oro origen primario del tumor. El carcinoma papilar de tiroides se debe diferenciar de otros tipos de adenocarcinoma; para esto se realizan pruebas de inmunohistoquímica en los cortes de 


\section{Tabla I. Clasificación de los tumores de la nasofaringe según la AJCC}

\section{Tumor (T)}

\begin{tabular}{|l|l|}
\hline Tx & No puede evaluarse el tumor primario \\
T0 & No hay prueba de tumor primario \\
Tis & Carcinoma in situ \\
T1 & Tumor confinado a nasofaringe \\
T2 & Tumor se extiende a los tejidos blandos \\
T2a & Compromete la orofaringe o la fosa nasal sin extensión parafaríngea \\
T2b & Cualquier tumor con extensión parafaríngea \\
T3 & Tumor que invade estructuras óseas, senos paranasales o ambos \\
T4 & Tumor con extensión intracraneal o compromiso de nervios craneales o ambos, fosa infratemporal, hipofaringe, \\
& órbita o espacio masticatorio \\
\hline
\end{tabular}

\section{Ganglios linfáticos regionales (N)}

\begin{tabular}{|l|l|}
\hline Nx & No pueden evaluarse ganglios linfáticos regionales \\
No & No hay metástasis a ganglios linfáticos regionales \\
N1 & Metástasis unilateral en ganglio(s) linfático(s) no mayor de $6 \mathrm{~cm}$ en su mayor dimensión sobre la fosa supraclavicular \\
N2 & Metástasis bilateral en ganglio(s) linfático(s) no más de $6 \mathrm{~cm}$ en su mayor dimensión, sobre la fosa supraclavicular \\
N3 & Metástasis en ganglio(s) linfático(s) $>6 \mathrm{~cm}$ o la fosa supraclavicular \\
N3a & Más de $6 \mathrm{~cm}$ \\
N3b & Extensión a la fosa supraclavicular \\
\hline
\end{tabular}

\section{Metástasis a distancia (M)}

\begin{tabular}{l|l} 
Mx & No puede evaluarse la metástasis a distancia \\
Mo & No hay metástasis a distancia \\
MI & Presencia de metástasis a distancia
\end{tabular}

Agrupación por estadios del AJCC

\begin{tabular}{l|l} 
ESTADIO 0 & Tis, N0, M0 \\
ESTADIO I & TI, N0, M0 \\
ESTADIO IIA & TI, N0, M0 \\
ESTADIO IIB & TI, NI, M0,T2, NI, M0,T2a, NI, MO, T2b, N0, M0, T2b, NI, M0 \\
ESTADIO III & TI, N2, M0.T2a, N2, M0.T2b, N2, M0.T3, N0, M0, T3, NI, M0, T3, N2, M0 \\
ESTADIO IVA & T4, N0, M0, T4, NI, M0, T4, N2, M0 \\
ESTADIO IVB & Cualquier T, N3, M0 \\
ESTADIO IVC & Cualquier T, cualquier N, MI
\end{tabular}

patología. Los tumores similares a los tiroideos son positivos para TTF-1 y CK-7 y negativos para iroglobulina y CK20, los cuales son positivos en las variantes de origen intestinal y su curso es más agresivo. ${ }^{6}$

Chia-Hsiang Fu y Kai-Ping Chang describieron en Taiwán el caso de un paciente de sexo masculino de 68 años con cuadro clínico de sensación de globo faríngeo con hallazgos endoscópicos de masa pediculada adherida al techo de la nasofaringe, a quien se le realizó resección en bloque mediante translocación facial. El reporte de patología mostró adenocarcinoma papilar positivo para TTF-1 y CK-7 y negativo para CK-20 y tiroglobulina, además realizaron pruebas de PCR (reacción en cadena de polimerasa) para identificación del virus de Epstein Barr, siendo negativas. ${ }^{1,6}$ Karkos y R. Kelleher en Dundee, Reino Unido, reportaron un caso de un paciente de sexo masculino de 72 años con cuadro clínico de seis meses de otorrea serosanguinolenta e hipoacusia progresiva izquierda, con antecedente de resección de adenocarcinoma papilar de nasofaringe. En los estudios se observó compromiso a nivel de la mastoides y oído 
medio izquierdo; realizaron mastoidectomía radical y radioterapia y el informe de patología fue compatible con adenocarcinoma papilar de bajo grado; en este caso no se logró establecer el origen primario del tumor o si ambos correspondían a primarios, ya que no existía evidencia en la biopsia de diseminación a través de la trompa de Eustaquio. ${ }^{2}$ C. Andrew Van Hasselt reportó en Hong Kong en 1991 el primer caso de un paciente de sexo masculino de 28 años con una adenocarcinoma papilar de nasofaringe. Cursaba con obstrucción nasal y rinolalia de diez años de evolución encontrando a la evaluación endoscópica una masa pedunculada móvil dependiente del techo de la nasofaringe. Realizaron para su resección un abordaje transpalatal. A la histopatología se observó pleomorfismo e hipercromasia, fibras vasculares asociadas con cuerpos de psamoma, pruebas de inmunoperoxidasa negativas, incluyendo proteína S-100. ${ }^{4}$

Los casos reportados en la literatura corresponden a pacientes en su mayoría hombres, en zonas de Asia, Reino Unido y Norteamérica. ${ }^{1,6}$ Continúa siendo una patología rara a nivel de la nasofaringe, muchas veces subdiagnosticada en la valoración histológica. ${ }^{6}$ A pesar de que el carcinoma papilar de nasofaringe presenta un crecimiento complejo, invasión estromal y pleomorfismo citológico, es considerado un tumor de bajo grado de malignidad y es necesario descartar siempre el origen primario antes de realizar la resección, ante estudios de extensión para tórax, abdomen y verificar una adecuada función tiroidea. ${ }^{6}$ Dentro de los manejos para este tipo de lesiones se han utilizado abordajes transpalatales, translocación facial y cirugía endoscópica. En este caso se empleó la vía endoscópica transnasal logrando la resección con amplio margen de seguridad y con menor morbilidad posoperatoria para la paciente.

\section{Referencias}

1. Fu CH, Chang KP, Ueng SH, Wu CC, Hao SP. Primary thyroid-like papillary adenocarcinoma of the nasopharynx. Auris Nasus Larynx. 2008; 35: 579-582.

2. Karros PD, Kellerher R. Aggressive papillary tumor of the nasopharynx followed by an aggressive papillary tumour of the middle ear. A multiple site tumour. J Laryngol Otol. 2003 Dec;117(12):989-91.

3. American Joint Committee on Cancer. AJCC Cancer Staging Manual. 6th ed. New York : AJCC; 2002. p. 31-46.

4. Van Hasselt CA. Papillary adenocarcinoma of the nasopharynx. J Laryngol Otol. 1991 Oct; 105: 853-854.

5. Asociación Colombo Japonesa, Embajada de Japón. 75 años de la migración japonesa en Colombia. Cali: Asociación Colombo Japonesa; 2009.

6. Wenig BM, Hyams VJ, Heffner DK. Nasopharyngealpapillary adenocarcinoma. A clinicopathologic study of a low-grade carcinoma. Am J Surg Pathol. 1988 Dec;12(12):946-53. 